\title{
PELATIHAN PEMBUATAN SABUN CUCI MOBIL PADA NARAPIDANA LEMBAGA PEMASYARAKATAN KELAS IIA SIDOARJO
}

\author{
Faiz Fakhri Isjwara, M. Agung Bachtiar, Risang Achmad P.P1 \\ Prodi Teknik Pemasyarakatan, Politeknik Ilmu Pemasyarakatan, Indonesia \\ e-mail: faizfakhriisjwaraa@gmail.com
}

\begin{abstract}
Abstrak
Pelatihan pembuatan sabun cuci mobil ini bertujuan untuk menjalankan program kemandirian narapidana yang bertujuan untuk melatih serta meningkatkan kreatifitas narapidana di Lembaga pemasyarakatan kelas IIA Sidoarjo. Pelatihan pembuatan sabun cuci mobil melewati beberapa tahap seperti konsultasi kepada mitra SMK Negeri 3 Kimia Madiun, persiapan alat \& bahan yang dibutuhkan, sosialisasi terhadap narapidana, penyeleksian terhadap narapidana untuk mengikuti pelatihan pembuatan sabun cuci mobil, pelaksanaan pelatihan pembuatan sabun cuci mobil dan percobaan hasil sabun di tempat cucian mobil di Lembaga pemasyarakatan Kelas IIA Sidoarjo. Hasil produk sabun dikemas dalam botol ukuran 5 liter dan produk digunakan pada tempat cuci mobil yang berada dihalaman Lapas Sidoarjo. Pelatihan ini diharapkan dapat bermanfaat sebagai bekal untuk memulai usaha baru ketika sudah bebas nanti serta dapat menunjang dan menambah penghasilan keluarga.
\end{abstract}

Kata Kunci: Kreatifitas, Narapidana, Pembuatan Sabun Cuci Mobil

\section{Pendahuluan}

Dalam kehidupan bermasyarakat yang sangat kompleks ini pasti didalam masyarakat terjadi berbagai macam pidana yang disebabkan karena tuntutan untuk memenuhi kebutuhannya sehari-hari. Perbuatan pidana yang terjadi masyarakat mengharapkan adanya hukuman setimpal atas perilakunya untuk mencapai rasa keadilan dalam masyarakat (Bambang Waluyo, 2004). Pemerintah berusaha menangani pelaku tindak pidana dengan cara membentuk badan hukum yang bertujuan untuk menegakkan keadilan dan menjadi sarana pengayoman bagi masyarakat. Pelaku tindak pidana akan mendapatkan sanksi pidana berbentuk menjalani hari hari dengan masa hukuman dalam Lembaga Pemasyarakatan. Lembaga Pemasyarakatan mempunyai peran penting dalam pembinaan narapidana untuk merubah narapidana menjadi warga negara yang baik dan dapat diterima kembali ditengahtengah masyarakat (Nindya Agustin Listyaningrum, 2013).

Pelaksanaan pembinaan narapidana ini berdasarkan putusan oleh Departemen Kehakiman Republik Indonesia berdasar keputusan Menteri Kehakiman RI No. M. 022- 
PK.04.10 Tahun 1990. Didalamya terdapat 2(dua) pola pembinaan yaitu pembinaan kepribadian dan pembinaan kemandirian. 1) Pembinaan kepribadian adalah model pembinaan yang berfokus pada pembinaan mental, spiritual dan jasmani. Bentuk lainnya adalah pendidikan formal yang berada di Lembaga Pemasyarakatan Kelas I Malang yang telah bekerjasama dengan Dinas Pendikan Kota Malang untuk memenuhi pendidikan narapidana yang belum memiliki ijazah dan pendidikan ini berjalan seperti sekolah pada umumnya. 2) Pembinaan Kemandirian adalah program pembinaan keterampilan \& bimbingan kerja. Pembinaan ini berfokus pada pengembangan potensi, minat, bakat yang dimiliki narapidana. Kegiatan kemandirian di Lembaga Pemasyarakatan Kelas I Malang adalah kerajinan ukir kayu yang telah dipasarkan di Mall Sarinah dan Pasar Wisata Minggu Kota Malang (Erina Suhestia Ningtyas et al., 2013)

Narapidana mendapatkkan Pembinaan Kemandirian setelah melewati 1/3 (satu per tiga) masa pidana. Pembinaan kemandirian menjadi narapidana tersebut meyakini bahwa dirinya masih memiliki potensi produktif yang dapat berguna dalam pembangunan bangsa dan negara dengan cara diberi pelatihan keterampilan yang disediakan lapas agar dapat menjalani hidup secara mandiri dan bermanfaat bagi bangsa dan negara(Equatora, 2018)

Pelatihan pembuatan sabun cair oleh Elis Susiawati beserta dua rekan lainnya yang dilaksanakan di Desa Cibiru Wetan Kecamatan Cileunyi Kabupaten Bandung dapat juga digunakan sebagai referensi untuk program pembinaan kemaandirian pada narapidana karena memiliki manfaat berupa pengalaman baru serta kreatifitas dalam pembuatan sabun mandi cair(R. Herni Kusriani, Ika Kurnia Sukmawati, 2019)

Sebuah informasi penting untuk masyarakat secara umum bahwa narapidana dalam lembaga pemasyarakatan tidak hanya duduk diam dibalik jeruji besi dan menunggu hukumannya berakhir. Dalam peraturan perundang-undangan dijelaskan bahwa narapidana berhak mendapat pembinaan salah satunya adalah pembinaan kemandirian. Program pembinaan kemandirian inilah merupakan hal penting untuk melatih kemandirian narapidana agar setelah keluar lembaga pemasyarakatan mereka dapat menciptakan peluang usaha baru atau lapangan pekerjaan sendiri. Dalam hal ini tim memberikan program pelatihan pembuatan sabun cuci mobil yang diharapkan setelah bebas dapat berwirausaha sendiri dan menciptakan lapangan kerja sendiri. Dengan adanya program pembinaan kemandirian, narapidana dapat menerapkan ilmu yang telah diberikan untuk membuka peluang usaha mandiri dan dapat 
memenuhi kebutuhan ekonomi keluarga dengan cara yang tidak bertentangan dengan hukum yang berlaku.

\section{A. Masalah}

Permasalahan yang ada dalam pengabdian kepada masyarakat yang dilaksanakan pada Lembaga Pemasyarakatan Kelas IIA Sidoarjo adalah narapidana yang berada dalam lapas tersebut membutuhkan bimbingan pelatihan wirausaha keterampilan untuk dapat mengembangkan potensi diri dan dapat membuka usaha ekonomi sendiri pada saat mereka telah keluar dari lembaga permasyarakatan.

\section{Metode Pelaksanaan}

Metode yang digunakan dalam kegiatan pengabdian masyarakat adalah sebagai berikut:

a) Konsultasi dengan mitra, terkait dengan alat \& bahan yang dibutuhkan serta prosedur cara pembuatan sabun cuci mobil yang telah disediakan oleh mitra

b) Persiapan Alat \& Bahan

Petugas menyiapkan alat dan membeli bahan yang dibutuhkan untuk pembuatan sabun cuci mobil dalam jumlah yang sudah ditentukan oleh mitra.

c) Sosialisasi

Petugas melakukan sosialisasi kegiatan pelatihan pembuatan sabun cuci mobil kepada narapidana dalam lembaga pemasyarakatan

d) Seleksi

Pada tahap ini petugas melakukan seleksi pada narapidana yang akan mengikuti kegiatan ini berdasarkan minat dan bakat yang dimiliki oleh narapidana.

e) Pelatihan

Petugas melaksanakan tahap-tahap pelatihan secara langsung kepada narapidana berdasar prosedur yang telah diberikan oleh mitra dan dilakukan secara bertahap sesuai prosedur yang telah ditentukan.

\section{Pembahasan}


Pengabian masyarakat ini dilaksanakan di Lembaga Pemasyarakatan Kelas IIA Sidoarjo yang melibatkan mitra dari SMKN 3 Madiun, petugas pemasyarakatan, narapidana, berikut kegiatan yang dilakukan;

\section{a) Konsultasi dengan mitra}

Konsultasi dengan mitra dari SMKN 3 Madiun terkait alat \& bahan yang dibutuhkan serta prosedur pembuatan sabun cuci mobil. Pada tahap ini telah ditentukan alat \& bahan yang dibutuhkan serta langkah-langkah pembuatan sabun cuci mobil. Pada kegiatan ini hasil yang diperoleh adalah formula pembuatan sabun cuci mobil dan langkah-langkah pembuatannya yang tersaji dalam materi, materi tersebut akan dibagikan kepada narapidana untuk memudahkan pelatihan pembuatan produk sabun cuci mobil.

\section{b) Persiapan Alat dan Bahan}

Pada tahap ini petugas melakukan persiapan mulai dari alat yang dibutuhakan hingga bahan yang akan digunakan. Berikut adalah alat dan bahan yang dibutuhkan; 1) Wadah, 2) Timbangan, 3) Alat Pengaduk, 4) Lakmus, berikutnya bahan yang dibutuhkan; 1) Texavon $1 \mathrm{Kg}$, 2) LAS/Emal $\frac{1}{2} \mathrm{Kg}$, 3) Sodium sulfat $1 \mathrm{Kg}$, 4) Comperland/Foam Booster 1 ons, 5) Gliserin $\frac{1}{2}$ ons, 6) Pewarna biru $\frac{1}{4}$ ons, 7) Parfum 10ml, 8) Aquades 20 Liter.

\section{c) Sosialisasi}

Petugas melakukan sosialisasi terlebih dahulu kepada narapidana bahwa akan diadakan kegiatan pelatihan pembuatan sabun cuci mobil dalam lapas. Semua narapidana yang telah melewati $1 / 3$ masa pidana berhak untuk mengikuti pelatihan pembuatan sabun cuci mobil. Ruang pelatihan yang terbatas maka ditetapkan kuota untuk yang ingin mengikuti pelatihan.

\section{d) Seleksi}

Pada tahap seleksi, petugas melakukan seleksi pada narapidana yang telah mendaftar saat sosialisasi yang telah dilaksanakan. Petugas melakukan seleksi berdasarkan minat dan potensi bakat yang dimiliki narapidana dan petugas melakukan pendataan pada narapidana yang lolos untuk mengikuti pelatihan pembuatan sabun cuci mobil.

\section{e) Pelatihan}

Pelaksanaan konsultasi dengan mitra, persiapan alat \& bahan, sosialisasi, seleksi pada narapidana di Lembaga Pemasyarakatan Kelas IIA Sidoarjo telah dilaksanakan, maka tahap selanjutnya adalah pelatihan langsung pada narapidana yang dilaksanakan di dalam 
Ruang Kegiatan Kerja Lembaga Pemasyarakatan Kelas IIA Sidoarjo. Pelatihan menggunakan bentuk diskusi aktif pada narapidana dengan panduan pembuatan sabun cuci mobil yang tersaji dalam bentuk materi yang telah disediakan oleh mitra. Ruang Kerja Lembaga Pemasyarakatan Kelas IIA Sidoarjo dapat dilihat pada Gambar 1.

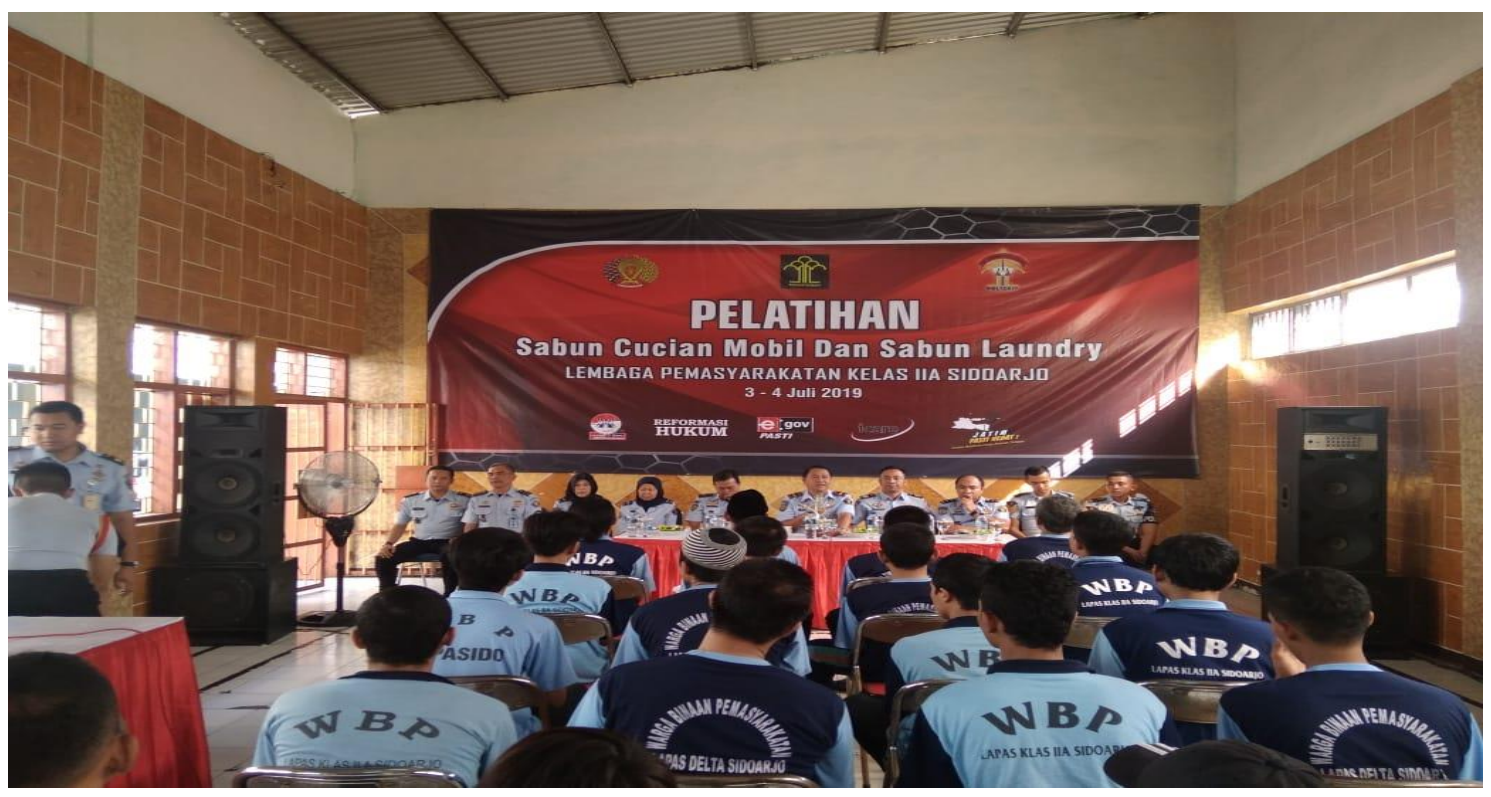

Gambar 1. Ruang Kerja Pembuatan Sabun Cuci Mobil

Pada tahap ini tim membimbing narapidana secara langsung untuk setiap prosesnya berdasarkan materi yang disediakan oleh mitra. Langkah kerja yang pertama adalah campurkan Sodium Sulfat $\frac{1}{2} \mathrm{Kg}$ dengan Texafon $1 \mathrm{Kg}$ dengan tambahan air sebanyak 15 Liter aduk rata selama 30 menit hingga menyatu menjadi warna putih, lalu tambahkan Emal dikit demi sedikit aduk hingga larut, lalu tambahkan Comperland/Foam Boaster kemudian tambahkan gliserin aduk hingga rata, selanjutnya tambahkan Sodium Sulfat $\frac{1}{2} \mathrm{Kg}$ dengan air sebanyak 5 Liter aduk hingga rata. Dan langkah terakhir adalah tambahkan pewarna biru lalu parfum sebanyak 10ml aduk hingga benar benar rata selama 60 menit serta atur kadar Phnya hingga 7 lalu simpan selama dengan wadah tertutup selama seharian untuk mendapatkan sabun cuci mobil terbaik. Proses pembuatan sabun cuci mobil dapat di lihat pada Gambar 2. 

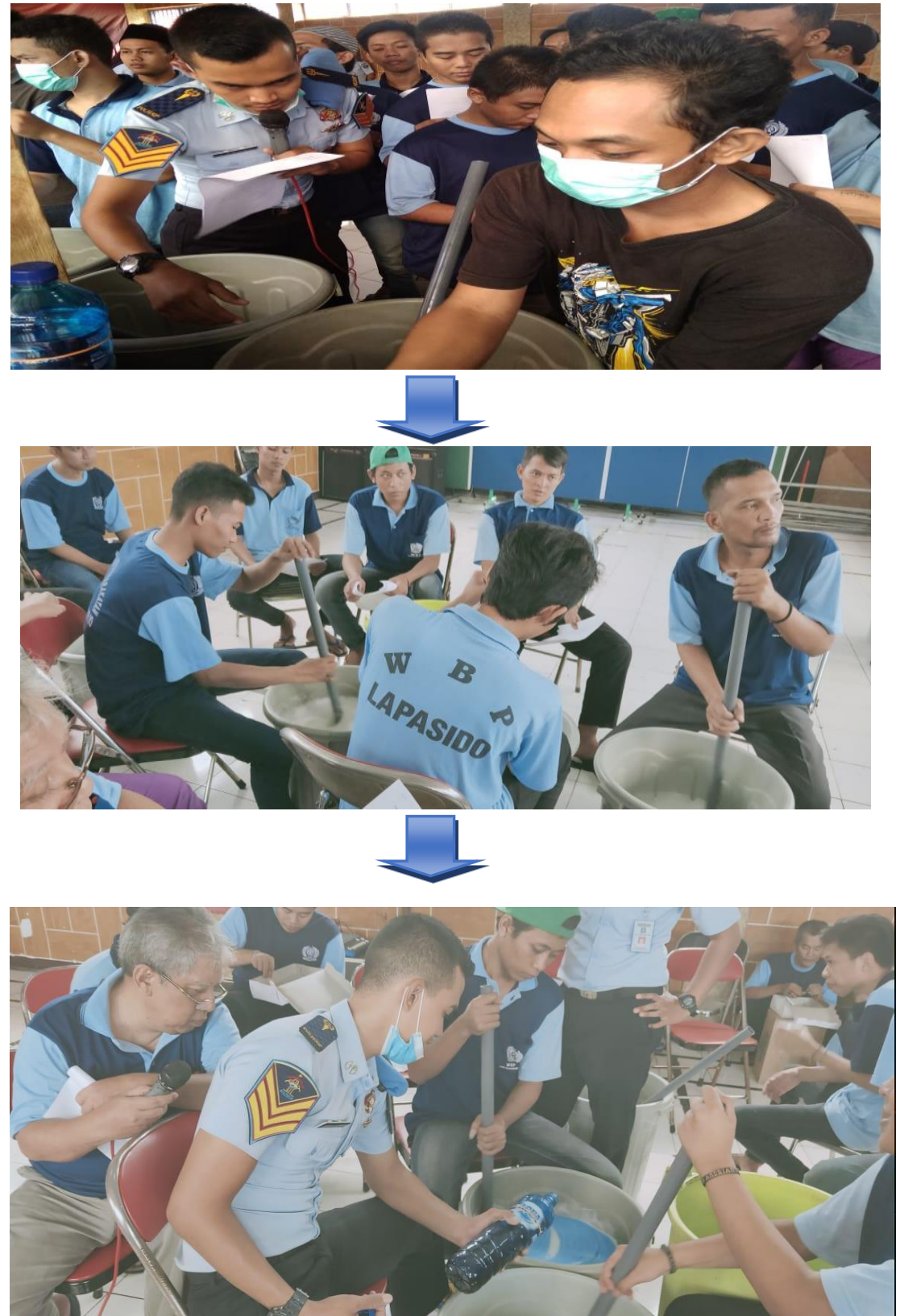

Gambar 2. Proses Pembuatan Sabun Cuci Mobil

Keesokan harinya hasil produk sabun cuci mobil telah siap untuk dikemas dalam wadah botol 5 Liter dan melakukan uji coba hasil produk di Tempat Cuci Mobil Lembaga Kelas IIA Sidoarjo. Uji coba hasil produk dapat dilihat pada Gambar 3. 


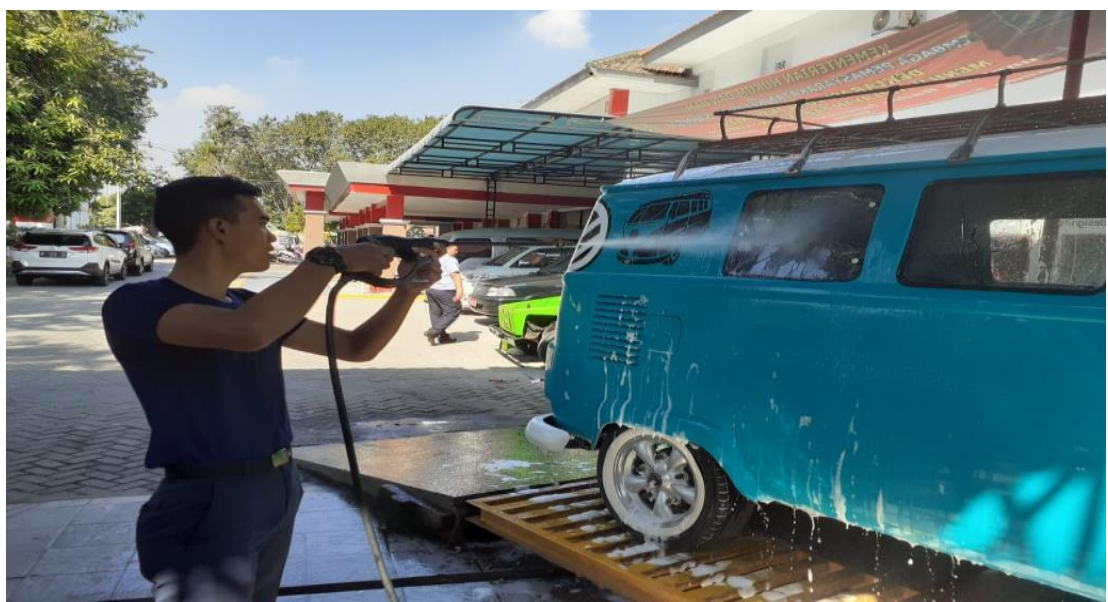

Gambar 3. Uji Coba Hasil Produk

\section{E. Kesimpulan}

Pada kegiatan pelatihan pembuatan sabun cuci mobil ini, semua tahapan dari pelaksanaan konsultasi dengan mitra, persiapan alat \& bahan, sosialisasi, seleksi dan pelatihan telah terlaksana dengan baik. Keberhasilan pelatihan pembuatan sabun cuci mobil ini dikarenakan narapidana dengan bimbingan tim melakukan langkah kerja sesuai prosedur diberikan oleh mitra. Dengan adanya pelatihan pembuatan sabun cuci mobil ini memberikan manfaat pada narapidana berupa kreatifitas. Harapan setelah bebas nanti pelatihan ini dapat bermanfaat sebagai bekal untuk memulai usaha baru ketika narapidana sudah bebas serta dapat menunjang dan menambah penghasilan keluarga.

\section{F. Ucapan Terima Kasih}

Ucapan terimakasih kami sampaikan pada Politeknik Ilmu Pemasyarakatan dan Pejabat Unit Pelaksana Teknis Lembaga Pemasyarakatan Kelas IIA Sidoarjo yang telah memberikan kesempatan untuk melaksanakan kegiatan pengadian masyarakat berupa pelatihan pembuatan sabun cuci mobil kepada narapidana. Juga kepada dosen pembimbing yang telah membimbing kami hingga terlaksananya kegiatan ini dengan baik. Terima kasih kepada semua rekan yang telah membantu kelancaran kegiatan ini.

\section{DAFTAR PUSTAKA}

Bambang Waluyo. (2004). Pidana Dan Pemidanaan. Sinar Grafika.

Equatora, M. A. (2018). Efektivitas Pembinaan Kemandirian Narapidana di Lembaga 
Pemasyarakatan Wirogunan Yogyakarta. EMPATI: Jurnal Ilmu Kesejahteraan Sosial, 7(1), 19-26. https://doi.org/10.15408/empati.v7i1.9648

Erina Suhestia Ningtyas, Abd. Yuli Andi Gandi, \& Sukanto. (2013). Pelaksanaan Program Pembinaan Narapidana pada Lembaga Pemasyarakatan dalam Rangka Pengembangan Sumber Daya Manusia (Studi pada Lembaga Pemasyarakatan Klas IA Lowokwaru Kota Malang). Jurnal Administrasi Publik (JAP), 1(6), 1266-1275.

Nindya Agustin Listyaningrum. (2013). Optimalisasi Pembinaan Narapidana di Lembaga Pemasyarakatan sebagai Upaya Mencegah Terjadinya Recidive.

R. Herni Kusriani, Ika Kurnia Sukmawati, E. S. (2019). Pelatihan Teknologi Tepat Guna Pembuatan Sabun Cair Pada Ibu-ibu PKK di RW 9 dan 17 Desa Cibiru Wetan Kecamatan Cileunyi Kabupaten Bandung. Pengadbdian Kepada Masyarakat, 3(1). 